\title{
An Analysis of the Environment of Cultivating Enterprises Maker Culture in Henan Province
}

\author{
Shanfu Yu \\ Huanghe Science and Technology College \\ Zhengzhou, China 450063
}

\begin{abstract}
The term "Chuangke" derives from the English word "Maker" initially, which originally refers to the individuals and groups who love science and technology and practice. They often share creativity and exchange ideas for pleasure. In general, they have common interests and different technical specialty. The makers gather together, work together, coordinate each other, and strive to transform the creative idea to reality. When they play their own specialty in the team, they can show great innovation and vitality outside. Maker culture is the product of social development and scientific and technological progress, and innovation, practice and sharing are its most significant feature. It firstly appeared in Europe and American and gradually grows and develops. In the context of innovation and entrepreneurship, how the enterprises in Henan Province create a good maker culture is of great significance for the full implementation of the national strategic deployment of "13th five-year plan of promoting the rise of central region" and innovation-driven economic restructuring and development.
\end{abstract}

Keywords-maker spirit; maker culture; innovative spirit; culture nurturing

\section{INTRODUCTION}

On January 28, 2015, Premier of the State Council Li Keqiang established the policy to support the development of "maker space" at the executive meeting of the State Council. Since then, the maker has taken root in the country as a culture instead of a phenomenon. At the Third Session of the Twelfth National People's Congress, "maker" was first written into the report on the work of the government. After the introduction of "the notice of work related to work program of the provincial double base construction of Henan Provincial Development and Reform Commission" in Henan Province, (Yu Development and Reform technology [2017] 210) and other documents, in order to promote the deep development of innovation and entrepreneurship work, we must optimize our ecological environment of entrepreneurship and innovation. The enterprise as the main body of innovation and entrepreneurship should cultivate business culture and stimulate the innovation vitality of staff, which is significant for the work of entrepreneurship and innovation.

Project basis: pilot project of major comprehensive reform in colleges of Henan province in 2016. Major code: $120201 \mathrm{~K}$

\section{THE DEVELOPMENT SITUATION OF ENTERPRISES MAKER CULTURE IN HENAN PROVINCE}

\section{A. Maker Culture in America}

America is the birthplace of maker culture. The American "garage culture" is a portrayal of maker culture, of which the essence is creation and innovation, as well as the curiosity and desire to the unknown world. In 2014, US President Barack Obama once pointed out that American should give full play to and release their imagination, and adhere to the road of innovation. The American people should become the creators of the world rather than simply consumers. With the advancement of American industrial Internet strategy, the construction of maker culture in the United States began to attract more and more attention, and the maker space was established in many universities and enterprises in the United States as the carrier of maker culture.

\section{B. Maker Culture in China}

In China, maker movement began to rise in 2010, and enter the rapid development stage in 2015. At present, the four major circles of maker culture centering on Beijing, Shanghai, Shenzhen, Hangzhou has basically formed. Shenzhen has the most complete maker industry chain in China; Shanghai has a strong atmosphere of innovation; Beijing converges top technical talent, art talent and capital institutions; Hangzhou has the best ecological environ ment of innovation and entrepreneurship based on "Internet + ". Our country have introduced policies to encourage the development of maker space and foster maker culture to promote the deep implementation of innovation and entrepreneurship work, so maker movement has become common practice.

\section{The Status Quo of Construction of Maker Culture in Henan Province}

In 2017, Henan Province has introduced new policies and regulations and local documents successively to encourage innovation and guide innovation, to support the entrepreneurship and innovation work in Henan Province. Various cities have also introduced corresponding preferential policy to encourage innovation, and put forward the requirements and countermeasures of the construction of maker culture and ecological system of entrepreneurship 
and innovation. For example, High-tech District of Sanmenxia proposed the entrepreneurship and innovation culture construction projects, including three aspects of endeavoring to cultivate innovative entrepreneurship culture, strengthening science and technology and its popularization, and nurturing entrepreneurial spirit; Economic Development district of Zhengzhou proposed to implement entrepreneurship and innovation ecological construction projects to optimize the basis Environment; Kaifeng put forward entrepreneurship and innovation culture construction projects, created entrepreneurship and innovation brand of Kaifeng, strengthened the publicity of entrepreneurship and innovation, carried out a series of activities, and organized "Entrepreneurial Innovation Competition" to vigorously promote entrepreneur training activities, to form the project import capacity facing domestic and international market. It also created a relaxed and comfortable atmosphere of entrepreneurship and innovation culture through the establishment of encouraging innovation failure mechanis $\mathrm{m}$ while continuing to promote the typical case of entrepreneurship and innovation, cultivate entrepreneurship and innovation spirit, optimize the environment, and provide protection for entrepreneurship and innovation.

The innovation and entrepreneurship work carried out by enterprises in Henan to cultivate maker culture has also made brilliant achievements. For example, Henan Cologne Group set up the first maker space of manufacturing industry in Xinxiang in July 2015, which provide good platform services through combining upstream and downstream and related research institutions to help to provide the platform for Cologne employees and young people with thoughts and creative ideas in the society to realize the creativity and exchange creative ideas, and construct a paradise for innovator. Up to the end of 2016, the total assets of enterprises are 250.77 million yuan, with year-on-year growth of $9.6 \%$; it achieves the main business sales income of 524.76 million yuan, with year-on-year growth of $9.02 \%$. China Yituo has set up 18 labor model innovation studio named after the model's names, centering on the two major tasks of tackling the problems of innovation and apprenticeship, with an average annual project of 287, of which 279 have been successfully implemented. They also got 9 national patents, which has become an important innovation base and source of enterprises.

\section{THE TIME CHARACTERISTICS OF MAKER CULTURE}

Maker culture not only creates a brand new industry and business model, but also brings new inspiration to the transformation of our economic development model, which has a significant impact on the enterprise cohesion, gathering wisdom, stimulating entrepreneurship, encouraging innovation, mining people's ingenuity to largest extent, and promoting innovative and harmonious development of society and plays a positive role in promoting the construction of enterprise innovation culture and the implementation of innovation-driven development.

\section{A. Innovation is the Soul of Maker Culture}

From the initial creative design and planning to the later creation and exploration, makers present the pioneering and fighting spirit of "dare to be the first in the world" everywhere. They are not restricted by the old system and model, and dare to break the traditional undesirable customs. They always endeavor to explore and discover the problems through action and practice with clinging attitude and courage, and find the solutions and countermeasures through innovation. Innovation spirit runs through the whole process of entrepreneurial practice of maker groups, and innovation is always its soul.

\section{B. The Essence of Maker Culture is Hard Work and Sharing}

Each fruit and achievement of maker groups is the quintessence of their hardworking and sweat as well as the result of active spirit. The maker groups must have the power and active spirit to develop their own business. If they lack active spirit and sharing idea, however glorious entrepreneurship, innovation and creativity cannot be achieved, and the expected innovation goal and desire will fail. The innovative products of maker groups should be beneficial to the results sharing in the human world. If they don't have such realm, maker spirit will lose the value and vitality, and it will not have such a great influence and attraction, which is the most flashing point of maker culture.

\section{The Essence of Maker Culture is Inclusiveness and Openness}

The maker groups can transform the world, benefit man kind through their own efforts and practice, and are able to share the results brought about by the progress with more people with an open posture and inclusiveness. This open and inclusive spiritual trait is embodied in every outstanding results of creation and innovation of maker groups. Openness and inclusiveness are the essential characteristics of the maker spirit and maker culture. The integration and agreement of maker spirit further enhance the time characteristics and sociality of maker culture in enterprises.

\section{The Main Makers of the Maker Culture Construction}

The group of people who are eager to learn, good at thinking, and with enthusiasm, courage, ideals, knowledge, skills, and pursuit, and appreciate practice and dare to innovate dare to break the authority, promote open source culture, and are willing to share and exchange. The entrepreneurial team they form has the team spirit of unity and harmony, sharing happiness and sorrow, and working together and the pioneering fighting spirit of being brave enough to bear, daring to be responsible. This is the huge source of energy of maker groups as well as the indis pensable subjective basic guarantee of maker culture. 


\section{E. Construction of Maker Culture is the Guarantee of Implementation of Entrepreneurship and Innovation Work}

The kernel keywords of maker culture are "innovation", "creation" and "vitality". At the Fifth Plenary Session of the 18th Communist Party of China, innovation development is raised to the level of the national strategy, and China has entered a new era of entrepreneurship and innovation. To achieve the strategic rise of the central region, speed up the construction of Free Trade Area in Henan province, we must adhere to innovation-driven development based on the five national development strategies and continue to promote the innovation in theory, system, and culture and place innovation in the strategic core location of overall development of Henan Province. We can release new needs for economic development by promoting the entrepreneurship and innovation work of Henan Province, and optimize the supply reform, to ultimately promote the comprehensive and coordinated development of economy in Henan Province.

\section{PROBLEMS IN CONSTRUCTION OF ENTERPRISES MAKER CULTURE OF HENAN PROVINCE}

With the development of market economy and the continuous deepening of the reform of enterprise system mechanis $\mathrm{m}$, the majority of enterprises in Henan Province attaches great importance to the spirit and culture construction of enterprises, and have achieved remarkable results through various joint efforts, which greatly promotes the innovative development of enterprises. However, there is still a certain gap between the requirements of current entrepreneurship and innovation work, which mainly reflects in the following aspects.

\section{A. The Understanding of Maker Culture Is not Deep Enough}

The soul of maker culture is innovation, so we must abandon the traditional values judging criteria, create the spirit of the time of self-employ ment, longing for innovation, fair competition, integrity and law-abiding and active participate in the construction of enterprises culture in the work. In reality, some operators and managers blindly chase the economic benefits, but they ignore the spiritual and cultural construction of enterprises, let alone realizing the influence of culture construction on the appeal and cohesion of staff. They also cannot recognize culture have the immense effect to unify the interests, needs, goals, and behavior of all the staff, or realize that it is the most profound foundation and the most fundamental elements of management, innovation and enhancing the core competitiveness of enterprises. These biased understanding and ideas not only affect the systematic and technological innovation of enterprises, but also seriously impede the innovation and development of enterprises culture.

\section{B. Team Spirit and Consciousness of Dedication of Staff Are not Strong}

Maker culture attach great importance to the value of "people first", that is, respecting the value of life of me mbers, as well as concerning about their spiritual pursuit. Currently, there is still the problem of not paying enough attention to the value of "people first" in cultural construction of some enterprises in Henan Province. "People first" is the lifeline of cultural construction of enterprises, so one-sided emphasis on material incentives will lead to the lack of concept of humanistic philosophy and humanistic spirit of enterprises. Such unbalanced development of "material" and "spirit" will make employees lack team spirit and consciousness of dedication, and thus cultural construction of enterprises will lose energy and vitality.

\section{Maker Culture Construction System Has not yet Formed}

Construction of maker culture is a long-term work, which can't be achieved at one stroke or get effect instantly. It needs the enterprises to combine their own advantages, attention of leader, cooperation of multi-sectors to carry out, and a systematic and comprehensive construction system is the guarantee. Driven by economic interests, some enterprises put pursuing economic interests in the first place, so they usually do not pay attention to cultural construction of enterprises, and lack long-term design and systematic planning for enterprise culture. Cultural construction in most of the enterprises remains in the slogan and system, instead of going deep into the mind of staff. At the same time, the staff strength of cultural construction is weak, and lack coordination mechanism, which restrict the healthy development of maker culture.

\section{COUNTERMEASURES OF CREATING CULTIVATION EN VIRONMENT OF MAKER CULT URE IN HENAN PROVINCE}

Creating the cultural at mosphere favorable to innovation of enterprises will plays a huge stimulating and promoting the role in the creative work of staff. Excellent in novative culture environment not only can stimulate the innovation enthusiasm of the staff, but also continue to encourage employees to think and create, so as to help enterprises to attract a large nu mber of outstanding talents to join.

\section{A. Carry Forward the Innovation Spirit of Enterprise}

The inheritance and promotion of the innovation spirit of enterprise is conducive to the cultivation of maker culture. The enterprises can use the human environment and material environment to imperceptibly affect the staff, and pay attention to the cultivation of staff's sense of innovation, innovative thinking and innovation ability, which can lay a good foundation for the formation of maker culture. The innovation spirit is the core culture with unique temperament formed in the survival and development of enterprises. The cultural core of independent thinking, innovation, and critical spirit contained in the innovation spirit of enterprise has great similarity with the connotation characteristics of maker culture, so we can stimulate the 
innovation vitality of the staff through the promotion of outstanding entrepreneurial spirit.

\section{B. Create Tolerant Culture Atmosphere}

Innovation is a process of continuous exploration and change, which has a lot of uncertainty, and the results are unpredictable and even most of the innovation will eventually fail. A successful innovation often needs to go through numerous failures, which is determined by the objective law of innovation. We must tolerate failure while advocating innovation. At present, within some enterprises, the failure of innovation cannot be correctly recognized and lack tolerance and encouragement, which will greatly dampen the enthusiasm of employees who are involved in innovation, and ultimately will lead the enterprise to miss development opportunities.

\section{Encourage Collaborative Innovation of Groups}

Technological innovation is a systematic project, which involves a number of innovative subjects and coordinated development of related organizations. The establishment of collaborative innovation mechanism among the various innovators can promote the innovation and transformation of achievements, and ensure the implementation of innovation. Various groups of enterprises should deal with the relationship among cooperation, competition and collaboration, which is conducive to the smooth development of innovation activities. The organization encourages joint innovation among employees and among enterprises, carries out competition and cooperation in innovation, and fully gives play to the innovation potential of group members. Thus they can form cooperative competition situation conducive to innovation inside and outside the organization, and ultimately achieve industrywide collaborative innovation.

\section{Establish Innovation Incentive Mechanism}

The construction of innovative talents team is the key to the achievement of innovation of enterprises. The loyalty of makers towards the organizations is determined by the organization's attitude towards knowledge and innovation behavior. The perfect incentive mechanism is essential to retain innovative talents. Enterprises should design a scientific and reasonable incentive system of reward to motivate staff, constantly optimize the quality of the work environment, and shape and guide the members of the innovative behavior with certain behavioral norms and measures, in order to achieve the common innovation vision of the organization and its members. They can constantly improve the innovation incentive mechanism through the organic combination of the spirit incentives and material incentives, analyze the needs of different employees, and give targeted incentives to ensure the continuity and consistency of policy.

\section{E. Foster a Sense of Responsibility and Mission of the Maker}

We should unify our thinking, extensively mobilize and publicize, cultivate the responsibility and mission awareness of wide makers in Henan Province and actively guide makers to carry out entrepreneurship and innovation work. Henan Province needs to make full use of official websites at all levels, the official mic roblog and government WeChat public account to timely interpret the information of policies and regulations related to entrepreneurship and innovation, and further improve the policy on entrepreneurship and innovation and construction of information services platform. We can publicize and commend the typical deeds and advanced models emerged in the entrepreneurship and innovation, and timely publicize and promote the successful experience. We can also make full use of the various exhibitions to comprehensively display excellent entrepreneurship and innovation results with high technological content, good social response, and strong driving force, and actively guide the enterprise to carry out the entrepreneurship and innovation culture in depth.

\section{REFERENCES}

[1] Mao Zeyang. Guangdong innovation and scientific research team open up the "test field" for the introduction of talents guangdong science and technology, 2010(3): 35-38

[2] He Dan. Research on the Construction of credibility culture in Private Architecture Enterprises Nanchang University, 2014

[3] Deng Xingzhou. Carry out the Scientific Outlook on Development comprehensively and Make Great Efforts to Create a New Situation of Family Planning Work of migrating Population in Beijing population and family planning, 2008(1): 16-18

[4] Han Licheng. Correctly handle the relationship between the construction of two civilizations to promote the spiritual civilization of our provinceto a new level Exploring and Reality, 1996(3): 3-7.

[5] Sun Jingyi. Research on Cultural Construction of Shandong Changxing Group. China University of Petroleum, 2015

[6] Wang Xiaoyong, Li Mingzhen, Jiangfen, Ning Jianrong. Study on the Countermeasures of Accelerating the Transformation of Scientific and Technological Achievements in Zhejiang Province. Science and Technology Management Research, 2012(16): 46-50

[7] Wang Lihong. On the Innovation Culture of State - owned Enterprises. Northeastern University, 2012.

[8] Tong Jiefang. Establishing Innovation Culture of Enterprise and Creating Innovation Environment in Enterprise Aerospace Industry Management, 2001(5): 24-27.

[9] Yuan Huaren. On the Construction of Grassroots Party Organizations in State-owned Construction Enterprises Oriental Enterprise Culture, 2014(10): 16-16.

[10] Niu Luqing. New forces of innovation in China New Economy Weekly, 2014 (12): 10-17.

[11] Yan Jingxi. Promote the construction of enterprise culture according to the requirements of advanced cultural. Journal of The Party School of Shengli Oilfield, 2003(4): 49-49.

[12] Zhang Qiaoyun. On the Construction of Advanced Enterprise Culture. Wuhan University, 2006. 